\title{
KONTRIBUSI BIMBINGAN AKADEMIK TERHADAP PRESTASI BELAJAR MAHASISWA JURUSAN ILMU PERPUSTAKAAN FAKULTAS ADAB DAN HUMANIORA UIN ALAUDDIN MAKASSAR
}

\author{
Himayah*
}

Pengutipan: Himayah. (2018). Kontribusi bimbingan akademik terhadap prestasi belajar mahasiswa jurusan Ilmu Perpustakaan Fakultas Adab dan Humaniora UIN Alauddin Makassar . Khizanah al-Hikmah : Jurnal Ilmu Perpustakaan, Informasi, dan Kearsipan. 6(2), 155-167.

DOI: https://doi.org/10.24252/kah.v6i2a7

*Universitas Islam Negeri Alauddin Makassar

Email korespondensi: himayah@uin-alauddin.ac.id

\begin{abstract}
ABSTRAK
Penelitian ini bertujuan untuk mengetahui apakah ada kontribusi bimbingan akademik untuk prestasi belajar siswa dan seberapa besar kontribusinya. Penelitian ini menggunakan metode penelitian korelasional kuantitatif, dengan populasi dan sampelnya adalah mahasiswa aktif. Studi ini menemukan bahwa ada kontribusi bimbingan akademik bagi mahasiswa. Diperoleh bahwa variabel Interaksi Dosen $(X)$ memiliki pengaruh yang signifikan terhadap variabel Prestasi Belajar Mahasiswa (Y), dan memiliki hubungan yang berbanding lurus. Ini ditunjukkan pada nilai t hitung (Korelasi Pearson) 0,665 lebih besar dari $r$ tabel, atau $r$ hitung $>r$ tabel $=0,665$ $>0,1982$. Lebih lanjut, penelitian ini menunjukkan bahwa kontribusi bimbingan akademik cukup signifikan. Hasil uji determinasi diperoleh bahwa nilai R2 adalah 0,442 yang berarti bahwa variabel Interaksi Dosen $(X)$ memiliki pengaruh terhadap variabel Prestasi Belajar Mahasiswa (Y) sebesar 44,2\%. Sedangkan sisanya 55,8\% dipengaruhi oleh faktor lain. Berdasarkan hasil analisis uji regresi keseluruhan pada variabel $X$, itu menunjukkan bahwa hipotesis pertama adalah bahwa ada pengaruh Interaksi Dosen terhadap Prestasi Belajar Siswa, terbukti benar. Artinya, pada setiap peningkatan nilai Interaksi Dosen, itu akan meningkatkan nilai Prestasi Belajar Mahasiswa. Ini menunjukkan bahwa interaksi dosen yang lebih sering dengan mahasiswa akan membantu siswa untuk mengatasi masalah dalam belajar, serta meningkatkan motivasi siswa.
\end{abstract}

Kata kunci: Bimbingan akademik; ilmu perpustakaan

\section{ABSTRACT}

This study aims to determine whether there is a contribution of academic guidance for the learning achievement of students and how much it contributes. This study uses a quantitative correlational research method, with populations and samples were active students. The study examined that there was a contribution of academic guidance for the student achievement. The results obtained that the Lecturer Interaction variable $(X)$ has a significant effect on the variable Student Learning Achievement $(Y)$, and has a relationship that is directly proportional. This is shown in the value of $t$ count (Pearson Correlation) of 0.665 greater than $r$ tabel, or $r$ count $>r$ tabel $=0.665>0.1982$. Furthermore, it indicated that the contribution of academic guidance was quite significant. The results of the determination test obtained that the R2 value is 0.442 which means that the Lecturer Interaction variable (X) has an influence on the Student Learning Achievement variable (Y) of $44.2 \%$. While the remaining $55.8 \%$ is influenced by other factors. Based on the results of the overall regression test analysis on variable $X$, it shows that the first hypothesis is that there is an influence of Lecturer Interaction on Student Learning Achievement, proven correct. That is, at each increase in the value of Lecturer Interaction, it will increase the value of Student Learning Achievement. This shows that the more frequent lecturer interaction with students will help students to overcome problems in learning, as well as increase student motivation.

Keywords: Academic guidance; library science 


\section{PENDAHULUAN}

\section{a. Latar Belakang}

Ada banyak faktor yang dapat menentukan keberhasilan mahasiswa dalam meraih prestasi terbaiknya di perguruan tinggi. Setidaknya, ada dua hal utama yang perlu mendapat perhatian dan dianggap memiliki pengaruh yang sangat besar terhadap prestasi belajar mahasiswa. Dua hal yang dimaksud adalah dosen penasehat akademik dan mahasiswa itu sendiri. Peran dosen penasehat adalah mengarahkan mahasiswa dalam mencapai tujuan belajarnya melalui bimbingan, baik dalam memfasilitasi kemajuan belajarnya maupun dengan membantu mencarikan solusi terhadap masalah-masalah lain yaitu kesulitan dalam belajar dan kendala kehidupan sosial yang dihadapi oleh mahasiswa. Dosen juga ditugasi memberikan bimbingan akademik kepada mahasiswa. Oleh sebab itulah, dosen mempunyai peranan ganda, yaitu sebagai pengajar dan sebagai Penasehat Akademik (PA).

Bimbingan akademik yang dilakukan oleh dosen secara inherent, dimaksudkan dengan memberikan bimbingan akademik agar mahasiswa dapat menyelesaikan studinya sesuai dengan rencana studi dan program perkuliahan dalam menyusun strategi belajar. Karena itu Penasehat Akademik berperan antara lain (Suryabrata, 1984): 1); Membimbing mahasiswa agar mereka benar-benar tahu dan memahami program studi yang diambilnya; 2) Membimbing mahasiswa agar mempunyai rancangan yang matang bagaimana menyelesaikan program studi yang dipilihnya; 3) Membimbing mahasiswa agar mempunyai strategi yang jitu dalam menyelesaikan program studinya; 4) Memotivasi mahasiswa agar meningkatkan kemauan belajar; 5)
Membimbing mahasiswa agar mereka memahami bagaimana prosedur dan tata cara menggunakan fàsilitas belajar; 6) Memupuk dan menanamkan jiwa ilmiah terhadap mahasiswa.

Dari observasi awal yang telah dilakukan di Jurusan Ilmu Perpustakaan Fakultas Adab dan Humaniora (FAH) Universitas Islam Negeri (UIN) Alauddin Makassar, ternyata hal tersebut tidak berjalan sebagaimana mestinya. Berdasarkan pengamatan peneliti dan hasil diskusi dengan beberapa mahasiswa, dapat dinyatakan bahwa sebagian besar mahasiswa datang ke Penasehat Akademik ketika akan menandatangani Kartu Rencana Studi (KRS). Hubungan dengan mahasiswa tidak begitu akrab, bahkan ada mahasiswa yang takut berurusan dengan penasehat akademiknya. Persepsi mahasiswa terhadap keberadaan Penasehat Akademik masih beragam dan belum terjalin hubungan yang harmonis antara mahasìswa dan penasehatnya. Oleh karena itu dianggap perlu untuk melakukan penelitian lebih lanjut tentang mengenai "Kontribusi Bimbingan Akademik Terhadap Prestasi Belajar Mahasiswa Jurusan Ilmu Perpustakaan Fakultas Adab dan Humaniora UIN Alauddin Makassar)"

\section{b. Rumusan Masalah}

1) Apakah ada kontribusi bimbingan akademik terhadap prestasi belajar mahasiswa Jurusan Ilmu Perpustakaan Fakultas Adab dan Humaniora UIN Alauddin Makassar?

2) Seberapa besar konstribusi bimbingan akademik terhadap prestasi belajar mahasiswa Jurusan Ilmu Perpustakaan Fakultas Adab dan Humaniora UIN Alauddin Makassar? 


\section{KAJIAN PUSTAKA}

\section{a. Penasehat Akademik}

Menurut buku "Pedoman Penasehat Akademik" UIN Alauddin Makassar, (2017), penasehat akademik (PA) adalah tenaga pengajar tetap yang telah mempunyai jabatan fungsional pada fakultas yang ditugaskan melaksanakan bimbingan akademik dan non akademik. Kepenasehatan akademik ialah usahausaha bimbingan yang dilakukan oleh PA bagi mahasiswa yang menjadi tanggungjawab bimbingannya. Usahausaha ini dilakukan dalam membantu mahasiswa dalam merencanakan program belajar, melaksanakan kegiatan belajar, mengatasi masalah belajar yang dihadapi, dan mengembangkan potensi-potensi yang dimiliki oleh mahasiswa bimbingannya.

Penasehat akademik (PA) bersifat membantu mahasiswa dalam mengambil keputusan yang berkaitan dengan proses akademik dan tidak menentukan arah maupun keputusan mahasiswa. Mahasiswa sendiri yang akan mengambil keputusan dan bertanggungjawab atas keputusannya tersebut. Bantuan yang dilakukan PA antara lain:

1) Memberikan informasi akademik yang relevan.

2) Pemberian orientasi program studi, pengembangan sikap dan kebiasaan belajar yang tepat dan benar.

3) Pemberian pertimbangan dan saransaran dalam proses pengambilan keputusan.

4) Pemberian contoh keteladanan, pemberian persetujuan atau penolakan atas sesuatu yang diajukan mahasiswa berdasarkan kelayakan dan ketentuan-ketentuan yang berlaku di lingkungan Universitas Islam Negeri Alauddin Makassar (UIN Alauddin Makassar, 2017).

\section{b. Prestasi Belajar}

Salah satu sasaran yang hendak dicapai dalam proses belajar adalah memperoleh keberhasilan dalam belajar. Keberhasilan tersebut berupa pengetahuan, kecakapan dan sikap seseorang yang terdidik. Melalui proses belajar akan terjadi perubahan-perubahan tingkah lakunya, memperbaiki perbuatannya, merencanakan konsepkonsep baru dan menemukan pengertianpengertian baru.

Prestasi belajar berasal dari gabungan kata prestasi dan belajar, merupakan hasil yang dicapai dari usaha untuk mendapat suatu keterampilan. Menurut As'ad (2005) prestasi belajar adalah hasil belajar yang dicapai oleh seseorang setelah ia melakukan aktivitas belajar dalam priode waktu tertentu. Dengan demikian prestasi belajar dapat dipilah-pilah menurut kurun waktu tertentu. Misalnya, prestasi belajar menurut satu semester, satu tahun, atau selama mengikuti program pendidikan tertentu. Menurut Arikunto (2012) prestasi belajar merupakan suatu hasil yang diperoleh sesudah belajar. Prestasi belajar ini biasanya dinyatakan dalam bentuk angka, huruf, atau kata baik, sedang, cukup dan kurang.

\section{METODOLOGI PENELITIAN}

\section{a. Jenis Penelitian}

Jenis penelitian ini adalah penelitian korelasional kuantitatif. Artinya, seluruh data penelitian yang terkait dengan bimbingan akademik yang diasumsikan memiliki hubungan korelasional dengan prestasi belajar mahasiswa Jurusan Ilmu Perpustakaan Fakultas Adab dan Humaniora UIN Alauddin Makassar. 


\section{b. Lokasi dan Waktu Penelitian}

Penelitian ini dilakukan terhadap para mahasiswa Jurusan Ilmu Perpustakaan Fakultas Adab dan Humaniora UIN Alauddin Makassar. Pemilihan lokasi penelitian ini didasari oleh beberapa hal sebagai berikut: 1) sesuai dengan sasaran penelitian; 2) mudah dijangkau dan ditelusuri keberadaannya karena berdekatan dengan lokasi peneliti berdomisili. Tahapan-tahapnan dalam penelitian ini dilakukan dalam semester Genap 2017/2018-Ganjil 2018/2019, antara Juli-November 2018.

\section{c. Populasi dan Sampel}

1) Populasi

Populasi penelitian adalah mahasiswa aktif Jurusan Ilmu Perpustakaan Fakultas Adab dan Humaniora UIN Alauddin Makassar. Mahasiswa aktif dalam hal ini adalah mahasiswa yang membayar UKT dan terdata di portal akademik UIN Alauddin Makassar.

Tabel 1. Distribusi Populasi Penelitian

\begin{tabular}{ccccc}
\hline No & Mahasiswa & \multicolumn{2}{c}{ Reguler } & Populasi \\
\cline { 3 - 5 } Jurusan Ilmu & $\mathrm{L}$ & $\mathrm{P}$ & & \\
Perpustakaan & & & & \\
FAH UINAM & & & \\
\hline Mahasiswa & 302 & 418 & 720 \\
Aktif & & & \\
\hline
\end{tabular}

2) Sampel

Teknik pengambilan sampel memakai teknik Stratified Proporsional Random Sampling dengan 10\% dari jumlah total populasi.
Tabel 2. Distribusi Sampel penelitian

\begin{tabular}{lllll}
\hline No & Mahasiswa & \multicolumn{2}{l}{ Reguler } & Sample \\
Jurusan Ilmu & L & P & \\
Perpustakaan & & & \\
FAH UINAM & & & \\
\hline Mahasiswa & 28 & 44 & 72 \\
Aktif $10 \%$ & & & \\
\end{tabular}

\section{d. Instrumen Penelitian}

Alat pengumpulan data yang digunakan dalam penelitian ini adalah angket yang disusun menurut model skala Likert, karena model ini dianggap paling cocok untuk mengetahui peranan penasehat akademik dan kebiasaan belajar mahasiswa. Pada model skala likert, jawabannya terdiri dari lima skala. dengan penetapan skor penilaian dari lima sampai satu, yakni 'sangat setuju', 'setuju', 'tidak setuju', 'sangat tidak setuju', dan 'tidak tahu'. Setiap butir dalam kuesioner diberi skor dan angka 5 4 - 3 - 2 - 1 . Bila pernyataan dalam angket bersifat positif, dan pernyataan bersifat negatif, maka masing-masing butir memiliki skor dari $1-2-3-4$ - 5. Angka ini digunakan untuk mengevaluasi variabel bebas yaitu peranan penasehat akademik (X). Angket ini akan diberikan kepada mahasiswa Jurusan Ilmu Perpustakaan Fakultas Adab dan Humaniora UIN Alauddin Makassar secara random.

\section{e. Uji Coba Instrumen}

1) Uji validitas instrumen

Untuk mengetahui validitas instrumen dilakukan melalui telaah terhadap construct validity dan content validity dengan melakukan konsultasi bersama pembimbing dan menetapkan butir-butir instrumen yang digunakan. Selanjutnya dilakukan uji coba instrumen untuk 30 mahasiswa lalu 
diolah dan dianalisis. Setelah data ditabulasikan, maka pengujian dilakukan dengan analisis faktor, yaitu dengan mengkorelasikan antar skor butir instrumen. Di sini digunakan teknik korelasi product moment dan pearson.

\section{2) Uji Reliabilitas Instrumen}

Instrumen yang diuji cobakan selanjutnya dihitung dengan menggunakan rumus Alpha Cronbach.

\section{f. Teknik Pengumpulan Data}

Dalam pengumpulan data ini digunakan instrumen berupa angket. Angket tersebut diharapkan dapat meliput data mengenai peranan penasehat akademik dan kebiasaan belajar mahasiswa. Pengumpulan data dilakukan secara langsung kepada mahasiswa yang menjadi sampel dengan mendapat bantuan dan teman sejawat.

\section{g. Analisis data}

Analisis yang akan digunakan untuk mendeskripsikan data adalah dengan menggunakan analisis regresi, di mana data diolah menggunakan alat analisis SPSS versi 22.0. Sebelum melakukan pengujian hipotesis, dilakukan uji prasyarat analisis yaitu:

1) Uji normalitas yang ditujukan untuk melihat dan mengetahui apakah data populasi berdistribusi normal atau tidak. Analisis dilakukan dengan menggunakan pendekatan teknik chi kuadrat

2) Uji homogenitas data untuk melihat apakah data yang diperoleh memiliki variasi yang homogen atau tidak. Uji homogen ini menggunakan chi kuadrat Bartlett

3) Uji Linearitas menggunakan teknik analisis regresi sederhana.
4) Menganalis independen antara variabel bebas dengan menggunakan teknik analisis korelasi product moment.

5) Pengujian hipotesis pertama dan kedua, menggunakan teknik analisis korelasi regresi sederhana, sedangkan untuk menguji hipotesis ketiga menggunakan teknik regresi ganda.

\section{HASIL PENELITIAN DAN PEMBAHASAN}

Berdasarkan jawaban dari 72 mahasiswa yang menjadi sampel dari populasi penelitian ini, maka di bawah ini dicantumkan tabulasi hasil angket tersebut dalam tabel-tabel distribusi frekuensi berdasarkan 2 variabel pènelitian, yaitu variabel independen $(X)$ interaksi dosen PA dengan mahasiswa bimbingan-dan variabel dependen $(Y)$ prestasi belajar mahasiswa.

\section{a. Variabel Interaksi Dosen PA dan Mahasiswa}

Berdasarkan data awal tentang interaksi dosen PA dan mahasiswa $(\mathrm{X})$, diketahui bahwa interaksi dosen dengan mahasiswa belum berjalan dengan baik, terlihat dari respon mahasiswa yang pada item-item tertentu berada pada skala kurang setuju dan tidak setuju.

Pada item/pernyataan no 1 tentang kemudahan menemui dosen PA, respon mahasiswa lebih banyak yang menyatakan kurang setuju, tidak setuju dan sangat tidak setuju terhadap kemudahan dalam menemui dosen PA, yaitu sebanyak 65,71 persen dari 70 reponden. Ini menunjukkan bahwa mahasiswa umumnya masih sulit untuk bertemu dosen PA dalam melakukan konsultasi-konsultasi. 
Hal itu diperkuat dalam respon mahasiswa pada beberapa pernyataan dalam variabel interaksi dosen PA dengan mahasiswa. Pada item rutinitas pertemuan dosen PA dalam satu semester, sebanyak 85 persen menyatakan kurang setuju, tidak setuju dan sangat tidak setuju. Ini menunjukkan bahwa pada umumnya mahasiswa jarang bertemu dengan dosen PA dalam satu semester. Demikian pula pada item konsultasi nilai dan IPK dengan dosen PA, sebanyak 74,29 persen mahasiswa menyatakan tidak melakukan konsultasi tersebut. Sementara pernyataan pada item konsultasi masalah di luar akademik dengan dosen PA justru lebih besar, ditunjukkan pada respon mahasiswa yang menyatakan kurang setuju, tidak setuju dan sangat tidak setuju terhadap realisasi item tersebut dengan dosen PA mereka.

Perhatian dosen PA kepada mahasiswa bimbingan juga terlihat sangat rendah, ditunjukkan pada item Dosen PA memberikan perhatian yang baik kepada mahasiswa bimbingan. Pada item ini, respon mahasiswa pada umumnya menyatakan kurang setuju, tidak setuju dan sangat tidak setuju dengan nilai total $64.29 \%$.

\section{b. Variabel Prestasi Belajar Mahasiswa}

Data awal variabel $\mathrm{Y}$ menjelaskan mengenai prestasi belajar mahasiswa. Dari 15 item pernyataan yang diberikan, variabel ini mendapatkan skala yang bervariasi, mengikut kepada interaksi mahasiswa dengan dosen PA.

Secara keseluruhan, respon yang diberikan terhadap item-item pernyataan yang ada, sebagian besar memberikan penilaian sangat setuju dan setuju. Meski interaksi mahasiswa dengan dosen PA belum berjalan baik sebagaimana dijelaskan dalam variabel interaksi dosen, namun prestasi belajar mahasiswa secara umum cukup bagus. Terlihat pada item nilai belajar mahasiswa setiap semester cukup baik, pada umumnya dijawab sangat setuju dan setuju, yakni dengan nilai 62,86 persen. Demikian pula item no 2 mengenai nilai IPK mahasiswa di atas 3, sebanyak 81,43 menyatakan sangat setuju dan setuju. Bagusnya prestasi belajar mahasiswa tersebut tampak tidak sejalan dengan peran dosen PA dalam membantu mahasiswa dalam mengatasi masalah belajar. Terlihat pada item no 5, pada umumnya mahasiswa menyatakan kurang setuju, tidak setuju dan sangat tidak setuju mengenai adanya bantuan dari dosen PA dalam mengatasi masalah mereka dalam belajar, yang mencapai 77,14 persen. Dosen PA juga dinilai tidak banyak memantau aktivitas belajar dan nilai mahasiswa setiap semester di mana, responden yang menjawab kurang setuju, tidak setuju dan sangat tidak setuju mencapai $77,14 \%$.

\section{Pembahasan}

\section{a. Uji Validitas}

Uji validitas konstruk dilakukan untuk mengukur sah atau valid tidaknya suatu kuesioner. Uji signifikansi dilakukan dengan membandingkan $r$ hitung dengan $r$ tabel atau nilai $p /$ sig dengan level of significance $(\alpha=0.05)$. Jika $r$ hitung $>r$ tabel atau $p$ atau sig $<0.05$, maka pernyataan item adalah valid. Pada penelitian ini, jumlah data adalah 70 , pada $a=0.05$, maka diketahui rtabel $=0,2352$. Berikut adalah hasil uji validitas : 


\section{Tabel 3. Hasil Uji Validitas}

\begin{tabular}{|c|c|c|c|c|c|}
\hline No & Variabel & Item & r-hitung & r-tabel & Keterangan \\
\hline 1 & \multirow{15}{*}{$\begin{array}{c}\text { Interaksi } \\
\text { Dosen PA }\end{array}$} & Inter-1 & 0.594 & 0.2352 & valid \\
\hline 2 & & Inter-2 & 0.603 & 0.2352 & valid \\
\hline 3 & & Inter-3 & 0.719 & 0.2352 & valid \\
\hline 4 & & Inter-4 & 0.665 & 0.2352 & valid \\
\hline 5 & & Inter-5 & 0.716 & 0.2352 & valid \\
\hline 6 & & Inter-6 & 0.669 & 0.2352 & valid \\
\hline 7 & & Inter-7 & 0.413 & 0.2352 & valid \\
\hline 8 & & Inter-8 & 0.547 & 0.2352 & valid \\
\hline 9 & & Inter-9 & 0.764 & 0.2352 & valid \\
\hline 10 & & Inter-10 & 0.804 & 0.2352 & valid \\
\hline 11 & & Inter-11 & 0.784 & 0.2352 & valid \\
\hline 12 & & Inter-12 & 0.668 & 0.2352 & valid \\
\hline 13 & & Inter-13 & 0.722 & 0.2352 & valid \\
\hline 14 & & Inter-14 & 0.450 & 0.2352 & valid \\
\hline 15 & & Inter-15 & 0.318 & 0.2352 & valid \\
\hline 16 & \multirow{15}{*}{$\begin{array}{c}\text { Prestasi } \\
\text { Belajar } \\
\text { Mahasiswa }\end{array}$} & Prest-1 & 0.303 & 0.2352 & valid \\
\hline 17 & & Prest-2 & 0.476 & 0.2352 & valid \\
\hline 18 & & Prest-3 & 0.318 & 0.2352 & valid \\
\hline 19 & & Prest-4 & 0.284 & 0.2352 & valid \\
\hline 20 & & Prest-5 & 0.695 & 0.2352 & valid \\
\hline 21 & & Prest-6 & 0.707 & 0.2352 & valid \\
\hline 22 & & Prest-7 & 0.749 & 0.2352 & valid \\
\hline 23 & & Prest-8 & 0.727 & 0.2352 & valid \\
\hline 24 & & Prest-9 & 0.732 & 0.2352 & valid \\
\hline 25 & & Prest-10 & 0.647 & 0.2352 & valid \\
\hline 26 & & Prest-11 & 0.666 & 0.2352 & valid \\
\hline 27 & & Prest-12 & 0.783 & 0.2352 & valid \\
\hline 28 & & Prest-13 & 0.696 & 0.2352 & valid \\
\hline 29 & & Prest-14 & 0.684 & 0.2352 & valid \\
\hline 30 & & Prest-15 & 0.688 & 0.2352 & valid \\
\hline
\end{tabular}

Jumlah data pada uji validitas ini adalah 70, berdasarkan tabel $\mathrm{r}$ dengan nilai sig $=0.05$, maka nilai $\mathrm{r}$ tabel adalah 0.2352 . Melalui tabel diketahui bahwa seluruh item memiliki $\mathrm{r}$ hitung $>0.2352$, maka disimpulkan item-item pada kuesioner valid digunakan sebagai alat ukur variabel.

\section{b. Uji Reliabilitas}

Reliabilitas adalah indeks yang menunjukkan sejauh mana suatu alat ukur (kuesioner) dapat dipercaya atau menunjukkan konsistensi dalam mengukur gejala yang sama. Nilai batas reliabilitas diukur menggunakan koefisien Alpha (Alpha Cronbach) yaitu 0,60. Berikut ini hasil adalah uji reliabilitas dari variabel penelitian: 
Tabel 4. Hasil Uji Reliabilitas

\begin{tabular}{clc}
\hline No & \multicolumn{1}{c}{ Variabel } & $\begin{array}{c}\text { Koefisien } \\
\text { Alpha }\end{array}$ \\
\hline 1 & Interaksi Dosen & 0.857 \\
\hline 2 & $\begin{array}{l}\text { Prestasi } \\
\text { Mahasiswa }\end{array}$ & 0.876 \\
\hline
\end{tabular}

Tabel 4. menunjukkan bahwa Koefisien Alpha (Alpha Cronbach) untuk setiap variabel dengan masing-masing pernyataan sebanyak 15 item, diperoleh nilai yang mendekati 1,0 , dan jauh di atas nilai batas Alpha Cronbach sebesar 0.60. Dengan demikian, seluruh variabel yang yang ada yaitu Interaksi Dosen dan Prestasi Belajar Mahasiswa dinyatakan reliabel dalam mengukur hal-hal yang ingin diukur (Hair Jr.et al, 1998: 60).

\section{c. Pengujian Asumsi Klasik}

Pengujian asumsi klasik diilakukan untuk mengetahui kondisi data yang ada guna menentukan model analisis yang tepat digunakan. Pada uji asumsi klasik ini terdiri dari uji Normalitas dengan menggunakan Kolmogorof-Smirnov, uji Multikolinearitas dengan VIF (Variance Inflation Factor), uji autokorelasi dengan Metode Durbin-Watson, dan Uji Heteroskesdatisitas dengan menggunakan metode Uji Spearman.

\section{1) Uji Normalitas}

Uji normalitas dilakukan bertujuan untuk mengetahui apakah residual dalam model regresi mengalami distribusi normal atau tidak. Bila residual tidak terdistribusi normal, berarti telah melanggar asumsi klasik, sehingga pengujian statistik menjadi tidak valid.

Tabel 5. Uji Normalitas

\begin{tabular}{lrrrrrrr}
\multicolumn{3}{c}{ Tests of Normality } \\
\hline & \multicolumn{3}{c}{$\begin{array}{c}\text { Kolmogorov- } \\
\text { Smirnova }\end{array}$} & \multicolumn{4}{c}{ Shapiro-Wilk } \\
\cline { 2 - 8 } & Statistic & df & Sig. & Statistic & df & Sig. \\
\hline Interaksi & .190 & 70 & $.200^{*}$ & .964 & 70 & .043 \\
\hline Prestasi & .215 & 70 & .075 & .972 & 70 & .114 \\
mahasiswa & & & & & & \\
\hline$*$
\end{tabular}

*. This is a lower bound of the true significance.

a. Lilliefors Significance Correction

Dari hasil tes normalitas yang menggunakan uji Kolmogorof-Smirnov, dapat dijelaskan bahwa data terdistribusi normal. Pada $\mathrm{N}=70$, diketahui nilai Tabel Kolmogorov $=0.160$. Distribusi normal ditunjukkan pada tabel 1.4., di mana nilai absolute untuk Interaksi Dosen adalah 0,190 dan Prestasi Belajar Mahasiswa adalah 0,215, yang semuanya lebih besar daripada nilai tabel Kolmogorov. Uji ini diperkuat dengan nilai yang ditunjukkan pada hasl uji probability, di mana nilai Interaksi Dosen adalah 0,200, dan Prestasi belajar Mahasiswa adalah sebesar 0,075, yang semua nilainya lebih besar daripada nilai $\alpha=0,05$. Dengan demikian dapat disimpulkan bahwa data yang digunakan dalam penelitian ini terdistribusi normal.

Tabel 6. Kesimpulan Distribusi Normal

\begin{tabular}{lllllll}
\hline No & Variabel & $\begin{array}{c}\text { Nilai } \\
\text { Absolue }\end{array}$ & Probability & Kolmogorof & a & Kesimpulan \\
\hline 1 & $\begin{array}{l}\text { Interaksi } \\
\text { Dosen }\end{array}$ & 0,190 & 0,200 & 0.160 & 0,05 & $\begin{array}{l}\text { Terdistribusi } \\
\text { Normal }\end{array}$ \\
\hline 2 & $\begin{array}{l}\text { Prestasi } \\
\text { Mahasiswa }\end{array}$ & 0,215 & 0,075 & 0.160 & 0,05 & $\begin{array}{l}\text { Terdistribusi } \\
\text { Normal }\end{array}$ \\
\hline
\end{tabular}


2) Uji Homogenitas

Uji Homogenitas digunakan untuk mengetahui varian dari beberapa populasi sama atau tidak. Uji dilakukan dengan menganalisis sampel $\mathrm{T}$ Test dan Anova:

a) Jika nilai signifikansi $<0.05$, maka dikatakan bahwa varian dari dua atau lebih kelompok populasi data adalah tidak sama

b) Jika nilai signifikansi > 0.05, maka dikatakan bahwa varian dari dua atau lebih kelompok populasi data adalah sama.

Tabel 7. Uji Homogenitas

\section{Test of Homogeneity of Variances}

\begin{tabular}{cccc}
\hline $\begin{array}{l}\text { Prestasi mahasiswa } \\
\text { Levene }\end{array}$ & & & \\
$\begin{array}{c}\text { Statistic } \\
\text { Sti }\end{array}$ & df2 & Sig. \\
\hline 4.079 & 1 & 68 & .147 \\
\hline
\end{tabular}

Berdasarkan tabel 7, diketahui bahwa populasi adalah homogen, terlihat dari nilai signifikansi adalah $0,147>0,05$

3) Uji Linearitas menggunakan teknik analisis regresi sederhana

Uji linearitas bertujuan untuk mengetahui apakah dua variabel mempunyai hubungan yang linear secara signifikan atau tidak. Data yang baik seharusnya terdapat hubungan yang linear antara variabel bebas dengan variabel terikat.

Variabel dinyatakan linear dengan melihat nilai siginifikansi. Jika nilai sig > 0,05, maka kesimpulannya adalah terdapat hubungan linear secara signifikan antara variabel yang digunakan.

Tabel . 8 Uji Linearitas

\begin{tabular}{|c|c|c|c|c|c|c|c|}
\hline \multicolumn{8}{|c|}{ ANOVA Table } \\
\hline & & & $\begin{array}{l}\text { Sum of } \\
\text { Squares }\end{array}$ & $\mathrm{df}$ & Mean Square & $\mathrm{F}$ & Sig. \\
\hline \multirow{5}{*}{$\begin{array}{l}\text { Prestasi mahasiswa } \\
\text { Interaksi }\end{array}$} & \multirow{3}{*}{ * Between Groups } & (Combined) & 28.156 & 32 & .880 & 2.631 & .003 \\
\hline & & Linearity & 17.932 & 1 & 17.932 & 53.626 & .000 \\
\hline & & $\begin{array}{l}\text { Deviation from } \\
\text { Linearity }\end{array}$ & 10.224 & 31 & .330 & .986 & .512 \\
\hline & Within Groups & & 12.372 & 37 & .334 & & \\
\hline & Total & & 40.528 & 69 & & & \\
\hline
\end{tabular}

Berdasarkan tabel 8, dapat diketahui bahwa nilai sig sebesar 0,512 , lebih besar daripada 0,05, maka dapat disimpulkan bahwa variabel yang digunakan dalam penelitian ini mempunyai hubungan yang linear.

\section{d. Hasil Pengujian Hipotesis dengan Regresi}

Persamaan regresi digunakan untuk meneliti hubungan antara sebuah variabel dependen dengan beberapa variabel independen.

1) Interaksi Dosen Penasehat Akademik (X) terhadap Prestasi Belajar Mahsiswa (Y) 
Untuk mengetahui apakah Interaksi Dosen PA (X) memberi pengaruh terhadap Prestasi Belajar Mahasiswa (Y), maka digunakan persamaan regresi yaitu:

\begin{abstract}
Olah data yang menggunakan software SPSS, diperoleh hasil sebagaimana ditunjukan dalam table 9.
\end{abstract}

\begin{tabular}{|c|c|c|c|c|c|c|c|}
\hline \multicolumn{8}{|c|}{$Y=\beta_{0}+\beta_{1} X_{1}+e$} \\
\hline \multicolumn{8}{|c|}{ Coefficients $^{a}$} \\
\hline \multirow[b]{2}{*}{ Model } & Unstandard & d Coefficients & $\begin{array}{l}\text { Standardized } \\
\text { Coefficients }\end{array}$ & & & Collinearity & tatistics \\
\hline & $\mathrm{B}$ & Std. Error & Beta & $\mathrm{t}$ & Sig. & Tolerance & VIF \\
\hline $1 \quad$ (Constant) & 1.137 & .258 & & 4.417 & .000 & & \\
\hline Interaksi & .699 & .095 & .665 & 7.346 & .000 & 1.000 & 1.000 \\
\hline
\end{tabular}

a. Dependent Variable: Prestasi mahasiswa

Berdasarkan tabel 9 di atas, diketahui nilai konstanta $\beta 0=1,137$ dan nilai koefisien $\beta 1=0,699$. Dengan demikian, dapat diperoleh hasil persamaan regresi:

$Y=1,137+0,699 \times 1$

Persamaan di atas menjelaskan bahwa bahwa ketika Interaksi Dosen PA (X) nilainya adalah nol, maka nilai Prestasi Belajar Mahasiswa adalah sebesar 1,137. Koefisien Variabel Interaksi-Dosen (X) sebesar 0,699 artinya jika variabel Interaksi Dosen mengalami kenaikan sebesar 2, maka variabel Prestasi Belajar Mahasiswa (Y) akan mengalami kenaikan sebesar 2×0,699 atau sama dengan 1,398.

Koefisien bernilai positif menunjukkan bahwa terjadi hubungan positif antara variabel bebas dengan variabel terikat. Bila Interaksi Dosen semakin besar, maka Prestasi Belajar Mahasiswa akan meningkat.

\section{a. Uji Pengaruh $\mathrm{t}$}

Uji $\mathrm{t}$ dilakukan untuk melihat ada tidaknya pengaruh variabel Interaksi
Dosen PA terhadap variabel Prestasi Belajar Mahasiswa. Berdasarkan jumlah data $\mathrm{N}=70$, diketahui nilai $\mathrm{t}$ tabel $=$ 7,346, maka dapat dapat simpulkan bahwa Interaksi Dosen memberi pengaruh yang signifikan terhadap Prestasi Belajar Mahasiswa. Hal ini dapat dilihat pada tabel 1.8., dari nilai t hitung ( $\mathrm{t}$ hitung $=3,443$ ) lebih besar daripada $\mathrm{t}$ tabel, atau:

\section{thitung $>\mathrm{t}$ tabel $=7,346>1,66757$}

Dengan demikian, hipotesis Ha dapat diterima yang berarti variabel Interaksi Dosen $(X)$ mempengaruhi peningkatan Prestasi Belajar Mahasiswa (Y) UINAM.

\section{b. Uji Korelasi}

Uji korelasi dilakukan untuk melihat hubungan antara variabel Interaksi Dosen $(X)$ dan variabel Prestasi Belajar Mahasiswa $(Y)$, ditandai dengan nilai $r$ hitung lebih besar daripada $r$ tabel. Dari hasil uji korelasi, diperoleh hasil seperti ditunjukkan pada tabel 1.9. 
Tabel. 10 Hasil Uji Korelasi $\mathrm{X}_{1}$

\begin{tabular}{|c|c|c|c|}
\hline \multicolumn{4}{|c|}{ Correlations } \\
\hline & & $\begin{array}{c}\text { Prestasi } \\
\text { mahasiswa }\end{array}$ & Interaksi \\
\hline \multirow[t]{2}{*}{$\begin{array}{l}\text { Pearson } \\
\text { Correlation }\end{array}$} & $\begin{array}{l}\text { Prestasi } \\
\text { mahasiswa }\end{array}$ & 1.000 & .665 \\
\hline & Interaksi & .665 & 1.000 \\
\hline \multirow[t]{2}{*}{ Sig. (1-tailed) } & $\begin{array}{l}\text { Prestasi } \\
\text { mahasiswa }\end{array}$ & 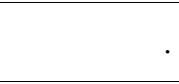 & .000 \\
\hline & Interaksi & .000 & \\
\hline \multirow[t]{2}{*}{$\mathrm{N}$} & $\begin{array}{l}\text { Prestasi } \\
\text { mahasiswa }\end{array}$ & 70 & 70 \\
\hline & Interaksi & 70 & 70 \\
\hline
\end{tabular}

Pada jumlah data $\mathrm{N}=70$, diperoleh nilai $\mathrm{r}$ tabel $=0.1982$, maka berdasarkan hasil perhitungan pada tabel 10, diketahui bahwa ada korelasi yang signifikan antara Interaksi Dosen (X) dengan Prestasi Belajar Mahasiswa (Y).
Hal ini ditunjukkan pada nilai $\mathrm{t}$ hitung (Pearson Correlation) sebesar 0,665 lebih besar daripada $r$ tabel, atau:

$$
\mathrm{r} \text { hitung }>\mathrm{r} \text { tabel }=0,665>0.1982
$$

c. Uji Determinasi R2

Untuk mengetahui besarnya pengaruh Interaksi Dosen $(X)$ terhadap peningkatan Prestasi Belajar Mahasiswa (Y) dilakukan dengan uji determinasi, dengan melihat nilai R2 ( $\mathrm{R}$ square). Dari analisis data yang telah dilakukan, diperoleh hasil sebagaimana pada tabel 4.16.

Tabel 11. Uji Koefisien Determinasi $X_{1}$

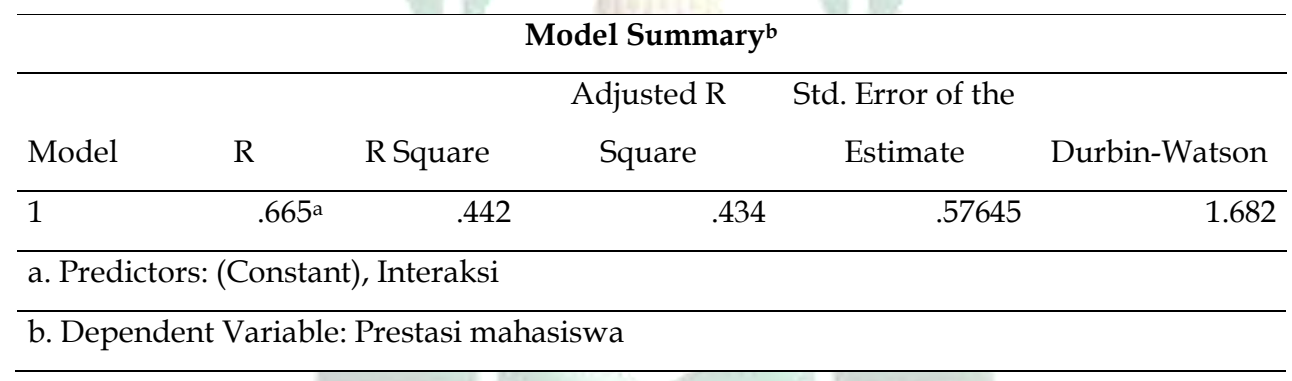

Dari hasil uji tersebut, diperoleh bahwa nilai $\mathrm{R} 2$ sebesar 0,442 yang berarti bahwa variabel Interaksi Dosen (X) memberi pengaruh terhadap variabel Prestasi Belajar Mahasiswa (Y) sebesar $44,2 \%$. Sedangkan sisanya, sebesar 55,8\% dipengaruhi oleh faktor lain.

Berdasarkan hasil analisis uji regresi keseluruhan terhadap variabel $X$, menunjukkan bahwa hipotesis pertama yaitu terdapat kontribusi atau pengaruh Interaksi Dosen PA terhadap Prestasi Belajar Mahasiswa, terbukti benar.

\section{KESIMPULAN DAN SARAN}

Berdasarkan analisis yang telah dilakukan, maka hasil penelitian dapat disimpulkan sebagai berikut:

a. Hasil penelitian menunjukkan bahwa ada kontribusi bimbingan akademik terhadap prestasi belajar mahasiswa Jurusan Ilmu Perpustakaan FAH UINAM. Dari uji regresi, diperoleh hasil bahwa variabel Interaksi Dosen (X) berpengaruh cukup signifikan terhadap variabel Prestasi Belajar Mahasiswa (Y), dan memiliki hubungan yang berbanding lurus. Dari hasil uji korelasi, diketahui bahwa ada korelasi yang signifikan antara Interaksi Dosen (X) dengan Prestasi 
Belajar Mahasiswa (Y). Hal ini ditunjukkan pada nilai $t$ hitung (Pearson Correlation) sebesar 0,665 lebih besar daripada rtabel, atau: $r$ hitung $>\mathrm{r}$ tabel $=0,665>0.1982$.

b. Hasil penelitian menunjukkan bahwa konstribusi bimbingan akademik terrhadap prestasi belajar mahasiswa Jurusan Ilmu Perpustakaan FAH UINAM cukup signifikan. Hasil uji determinasi diperoleh bahwa nilai R2 sebesar 0,442 yang berarti bahwa variabel Interaksi Dosen $(X)$ memberi pengaruh terhadap variabel Prestasi Belajar Mahasiswa (Y) sebesar 44,2\%. Sedangkan sisanya, sebesar 55,8\% dipengaruhi oleh faktor lain. Berdasarkan hasil analisis uji regresi keseluruhan terhadap variabel $X$, menunjukkan bahwa hipotesis pertama yaitu terdapat pengaruh Interaksi Dosen terhadap Prestasi Belajar Mahasiswa, terbukti benar. Artinya, pada setiap kenaikan nilai Interaksi Dosen, akan meningkatkan nilai Prestasi Belajar Mahasiswa. Ini menunjukkan bahwa semakin sering terjadi Interaksi Dosen dengan mahasiswa, akan membantu mahasiswa dalam mengatasi masalah dalam belajar, serta meningkatkan motivasi belajar mahasiswa.

\section{Saran}

a. Agar para dosen PA menyediakan waktu luang yang lebih banyak untuk membimbing mahasiswa, agar tugasnya dilaksanakan dengan optimal,

b. Dosen PA perlu lebih bertanggungjawab pada mahasiswa bimbingannya dan memberi pengarahan yang lebih tegas bagi pengembangan dan pembentukan karakter mahasiswa dengan menerapkan disiplin yang sudah diatur oleh pihak kampus.

\section{DAFTAR PUSTAKA}

Arikunto, S. (2012). Manajemen Penelitian. Jakarta: Rineka Cipta.

Arikunto, S. (2013). Metodologi Penelitian. Jakarta: Bumi Aksara.

Coliran, W. G. (2005). Sampling Techniques, New Delhi: Ensten Private.

Cronbach, L. J. (2001). Educational Psychology. New York: Harcount Braill World. Inc.

Ditjen Dikti. (2011). Pengembangan Unit Pelayanan Bimbingan dan Konseling di Perguruan Tinggi (Buku IV), Jakarta Direktorat Jendral Pendidikan Tinggi.

Ditjen Dikti. (1990). Pedoman Pelaksanaan Dan Tugas Penasehat Akademik, Jakarta: Direktorat Jendral Pendidikan Tinggi.

Gagne, R. (2005). M. The Condition of Learning. New York: Holt Rinchart and Winston, Inc.

Hamalik, O. (2011). Metode Belajar dan Kesulitan-Kesulitan Belajar. Bandung: Tarsito.

Jamarah, S.B. (2012). Prestasi Belajar Dan Kompetensi Guru. Surabaya: Usaha Nasional.

Jimenez, E.(1988). The Relative Efficiency Of Private And public Shools : The case Of Thailand. The World Bank Economic Review.

Mujiran. (1996). Teknik Dan Strategi Pelaksanaan Kepenasehatan Akademik. Makalah, IKIP Makassar.

Ngalim Purwanto, Psikologi Pendidikan, Bandung : Remaja Rosdakarya, 2011

Suryabrata, S. (2001). Proses Belajar Mengajar di Perguruan Tinggi. Yogyakarta: Andi Offset.

UIN Alauddin Makassar. (2017). Bidang Akademik dan Pengembangan Lembaga. Pedoman Penasehat Akademik. Makassar: UIN Alauddin. 
UIN Alauddin Makassar. (2016).

Pedoman Edukasi. Makassar : UIN

Alauddin.

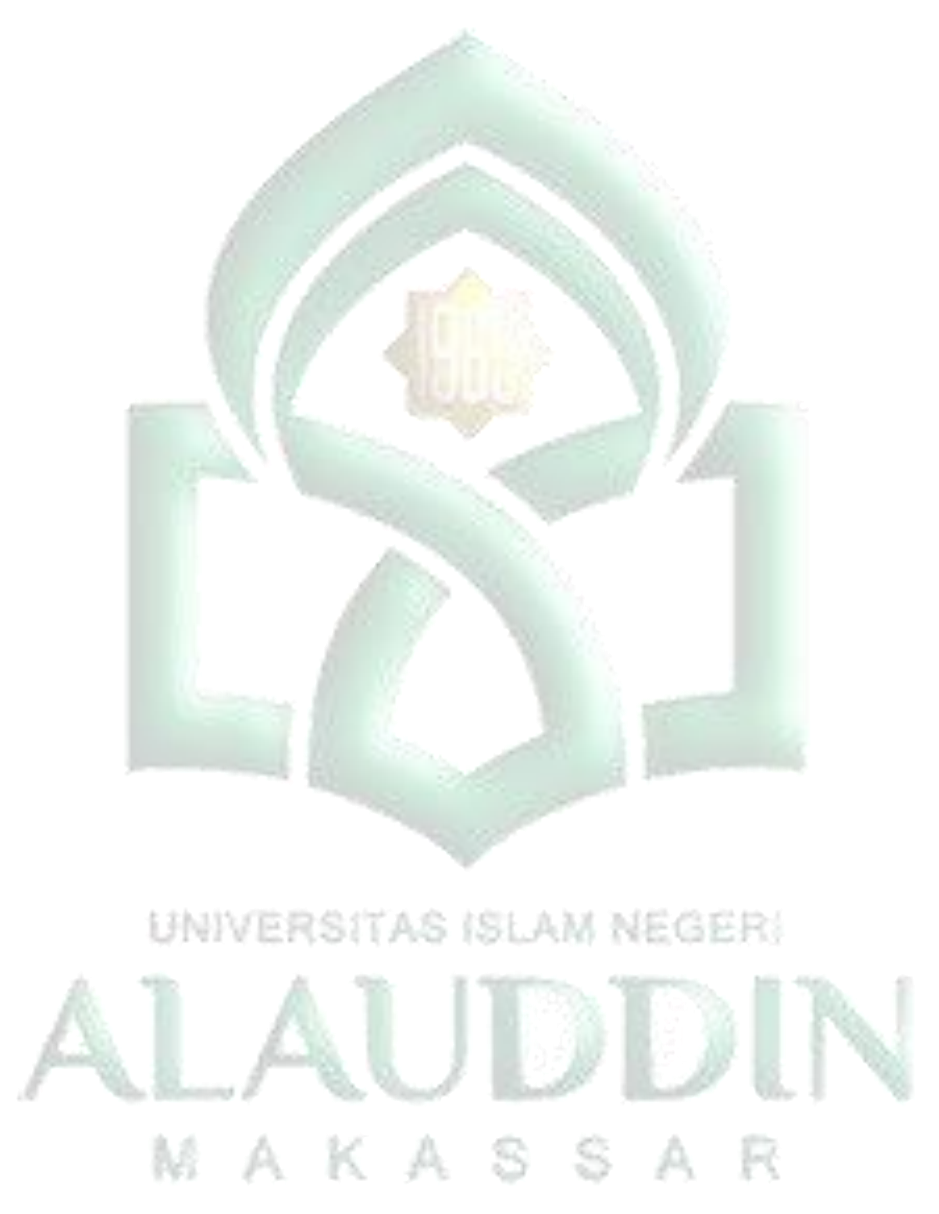

